\title{
Karayolu Kaplamalarının Sonlu Elemanlar Yöntemi İle Analizinde Gerilme- Birim Şekil Değiştirme Davranışına Etki Eden Parametrelerin İncelenmesi
}

\author{
Investigation of Finite Element Method Parameters Affecting the Displacement Behaviour \\ of Highway Pavements
}

\author{
Murat BOSTANCIOĞLU*
}

İnşaat Mühendisliği Bölümü, Mühendislik Fakültesi, Cumhuriyet Üniversitesi, Sivas, TÜRKIYYE

\author{
• Geliş tarihi / Received: 08.06.2018 • Düzeltilerek geliş tarihi / Received in revised form: 27.09.2018 • Kabul tarihi / Accepted: 01.10 .2018
}

\begin{abstract}
$\ddot{O} z$
Esnek kaplamalar bitüm ve granüler malzemeler ile inşa edilen bir üst yapı türüdür. Esnek üst yapıların projelendirilmesinde kullanılan yöntemler; ampirik yöntemler, kayma göçmesi sınıllama yöntemi, deplasman sınırlama yöntemi, regresyon yöntemi ve mekanistik ampirik yöntemler olarak beş kategoriye ayrılabilir. Bu yöntemler arasından geleneksel ampirik yöntemlerden mekanistik ampirik dizayn yöntemlerine doğru bir yönelme söz konusudur. Kaplama tabakalarının heterojenliği, dinamik ve tekrarlı yükleme koşulları gibi sebeplerle araştırmacılar çalışmalarını sonlu elemanlar yöntemi ile yapmayı tercih etmektedir ancak sonlu elemanlar modelinin 2 veya 3 boyutlu olarak tanımlanması, yükleme koşulları, tabakalar arası temas durumları ve formülasyonları, ızgara boyutları, sınır koşulları ve model boyutları gibi parametreler sonuçlar üzerinde önemli bir etkiye sahiptir. Bu çalışmada kaplama, temel ve alt temel tabakalarından oluşan geleneksel bir üst yapı kesiti üzerinde statik yükleme koşulları altında kaplama tepkilerini etkileyen parametreler incelenmiştir.
\end{abstract}

Anahtar kelimeler: Esnek üst yapılar, Kaplama tepkileri, Mekanistik-ampirik dizayn, Sonlu elemanlar yöntemi

\begin{abstract}
Flexible pavements are a type of superstructure constructed using bitumen and granular materials. The methods used in the design of flexible pavements can be examined in five categories. Empirical methods, limiting shear failure methods, limiting deflection methods, regression methods and mechanistic-empirical methods. There has been a dramatic change in the design methods for flexible pavements from the early purely empirical methods to the modern mechanisticempirical methods. Due to the heterogeneous pavement layers and dynamic and cycling loading instead of static loading, researchers diverted their research to the finite element method, which provides a better solution in the dynamic analysis of pavements while considering the heterogeneity. However, in finite element method, parameters such as the definition of the model as $2 D$ or $3 D$, the loading condition, the types and formulation of contact between layers, size of mesh, boundary conditions and dimensions of the model have a significant effect on the results. In this study, finite element model parameters affecting the pavement responses under static loading were investigated on a typical superstructure configuration consists pavement, base and subgrade layers.
\end{abstract}

Keywords: Flexible pavements, Pavement responses, Mechanistic-empirical design, Finite element model 


\section{Giriş}

Esnek kaplamalar bitüm ve granüler malzemeler kullanılarak inşa edilen bir üst yapı tipidir. Esnek üst yapıların tasarımında kullanılan yöntemler beş kategoride incelenebilir. Bunlar; kaplama kalınlığını tabakaların Kaliforniya taşıma gücü oranı (CBR) ile ilişkilendiren ampirik yöntemler, kaplama kalınlığı hesabında kayma göçmesini ve taban zemini veya yüzey deplasmanını sinırlamayı prensip olarak alan "kayma göçmesi sınırlama" ve "deplasman sinırlama" yöntemleri, ülkemizde Karayolları Genel Müdürlüğü tarafından esnek üst yapıların projelendirilmesinde kullanılan AASHTO yönteminin de içinde yer aldığ kaplama performansına veya yol testlerine bağlı regresyon yöntemleri ve mekanistik-ampirik yöntemler olarak siralanabilir. Günümüzde kaplama tasarımında, sadece sinırlı sayıda malzeme, yük ve çevresel etkiler ile yapılan yol testlerinden elde edilen verileri kullanan ampirik yöntemlerden mevcut trafik ve çevre etkileri altındaki kaplamanın tepkilerini (gerilme, şekil değiştirme, deplasman) mekanik teoriler ile hesaplayan mekanistik-ampirik yöntemlere bir yönelme söz konusudur (Huang, 2004; Zheng vd., 2012; Lu vd., 2014; Ahmed ve Erlingsson, 2016).

Burmister'ın elastik teorisi mekanistik-amprik yöntemler arasında en pratik ve sıklıkla kullanılan yöntem olarak bilinmektedir. Bu teorinin amac1 kaplama tabakası altındaki yatay çekme birim şekil değiştirmelerini ve taban zemini üzerindeki düşey basınç birim şekil değiştirmelerini sinırlamaktır (Huang, 2004; Ahmed ve Erlingsson, 2016). Yöntemde tabakaların sabit bir elastisite modülü (E) ve poisson oranına sahip (v) homojen, izotropik ve lineer elastik olduğu, malzemelerin ağırlıksız, tabakaların en alt tabaka hariç sonlu kalınlıkta (en alt tabaka yarı sonsuz) ve yükün dairesel bir alana uniform olarak etki ettiği kabulleri yapılmaktadır. Burmister yöntemi modifiye edilerek viskoelastik veya non-lineer elastik malzemelerden oluşan tabakalı yapıların analizinde de kullanılmaktadır (Huang, 2004; Zheng vd., 2012).

Karayolu üst yapı tabakalarının idealden uzak heterojen davranışları, trafik yüklerinin dairesel yerine farklı geometrideki temas yüzeyleri üzerine etki etmesi ve bu yüklerin statik yerine dinamik ve tekrarlı olması, dikdörtgensel kesitler yerine daha kompleks geometriler ve sınır koşulları ile çalışma zorunlulukları ve gelişen ve hızlanan bilgisayar teknolojisinin bir sonucu olarak, sonlu elemanlar metodu (SEM) son dönemde kaplama tepkilerini belirlemek için yaygın olarak kullanılan bir yöntem haline gelmiştir (Hadi ve Bodhinayake,
2003; Abd Alla, 2006; Yoo vd., 2006; Ambassa vd., 2013; Beskou vd., 2016; Sarkar, 2016).

SEM metodu 2 ve 3 boyutlu üst yapı modellerinin statik ve dinamik analizlerinde, lineer elastik ve viskoelastik olarak tanımlanan malzeme tiplerinde, farklı yükleme hızlarında, tek veya çift tekerlek yükü ve tekil, tandem, tridem aks yükleri altında, geogrid ile güçlendirilmiş kaplamaların analizlerinde başarıyla uygulanmıştır (Al-Azzawi, 2012; Beskou vd., 2016; Ahmed ve Erlingsson, 2016; Sarkar, 2016; Ahirwar ve Mandal, 2017). Ancak SEM metodunda modelin 2 boyutlu veya 3 boyutlu olarak tanımlanması, yükleme durumu, tabakalar arasındaki yüzeylerin temas tipleri, sonlu eleman 1zgarasının siklığı (mesh) ve oluşturulan modelin boyutları gibi parametreler sonuca önemli ölçüde etki etmekte ve metodun etkin kullanımı için uygun bir şekilde düzenlenmelidir.

$\mathrm{Bu}$ çalışmada taban zemini, temel ve kaplama tabakalarından oluşan tipik bir esnek üst yapı kesiti SEM metodu ile modellenmiş ve modelin kaplama tepkilerini doğru tahmin etmesi için gerekli değişkenlerin optimize edilmesi sağlanmıştır. Modelleme için ticari ANSYS 18.2 Workbench yazılımı kullanılmıştır. Hesaplanan gerilme ve birim şekil değiştirme değerlerine göre dönüşüm fonksiyonları yardımıyla yol ömrü hesab1 yapılarak SEM metodu değişkenlerinin bir esnek üst yapının ömrüne olan etkisi de ayrıca incelenmiştir.

\section{Materyal ve Yöntem}

\subsection{Model Geometrisi ve Sınır Koşullart}

Çalışmada eksenel simetrik geometride, taban zemini, temel ve kaplama tabakalarından oluşan bir üst yap1 kesiti seçilmiştir (Huang, 2004). Malzemeler lineer elastik olarak tanımlanmış ve özellikleri Şekil 1-a'da verilmiştir. Kaplama yüzeyine etki eden yük $122 \mathrm{~mm}$ yarıçapında dairesel bir alan üzerine $0.83 \mathrm{MPa}$ tekerlek iç basınc1 ile uniform olarak etki etmektedir. 3 boyutlu modelde simetriden dolay1 $1 / 4$ dairesel alan üzerine yükleme yapılarak analizler çalıştırılmıştır (Şekil 1-b). Kesiti oluşturan tüm tabakalar için herhangi bir süreksizlik olmadığı (çatlaksız tabaka) ve tabaka ara yüzeylerinin tamamen yapışık (bonded) olduğu değerlendirilmiştir (Hadi ve Bodhinayake, 2003).

Modelin sınır koşullarının tanımlanmasında aşağıdaki koşullar dikkate alınmıştır (Şekil 2'ye referansla); 
- Taban düzlemindeki (bcde) düğüm noktalarının düşey deplasmanları engellenmiştir

- (abcf) düzlemi, simetri düzlemi olduğu için yüke dik doğrultulardaki deplasmanlar engellenmiş, düşey deplasmanlar serbest bırakılmıştır.
- (cefg) düzlemi tekerleğin tam ortasından geçen düşey düzlem olduğundan yüke dik doğrultulardaki deplasmanlar engellenmiş, düşey deplasmanlar serbest bırakılmıştır (Hadi ve Bodhinayake, 2003).

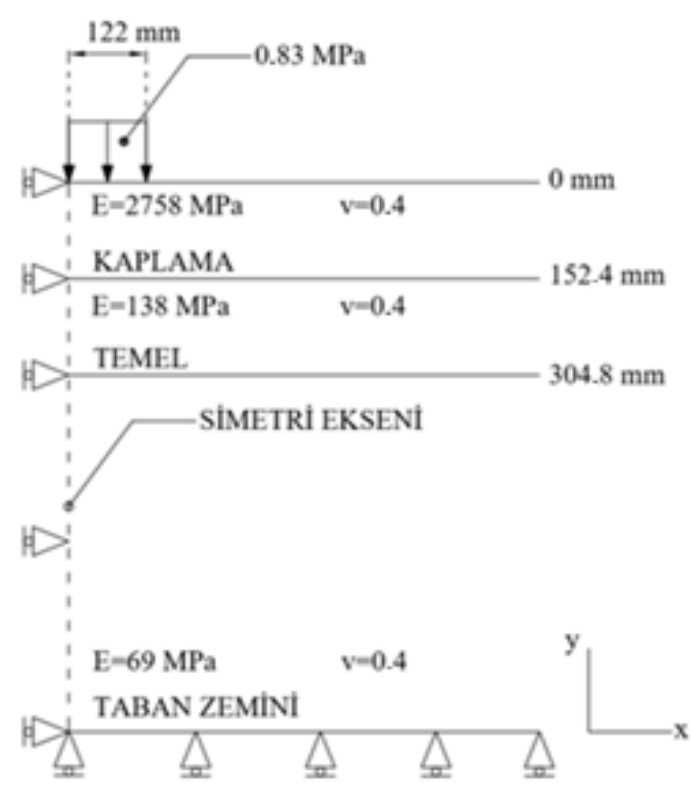

(a)

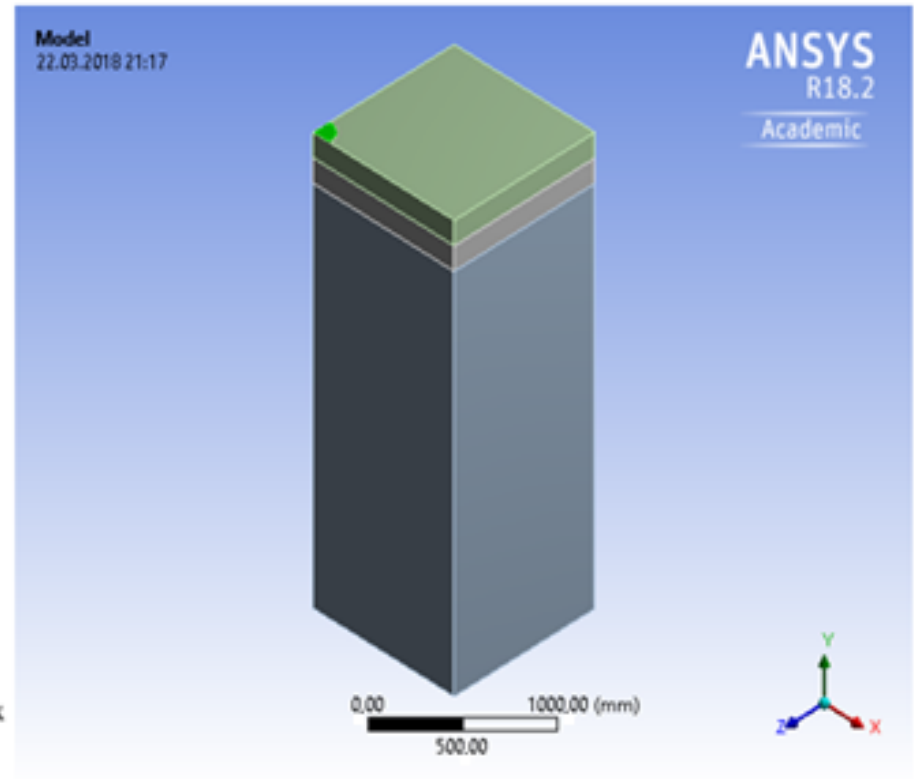

(b)

Şekil 1. (a) Üst yap1 en kesiti, (b) 3 boyutlu model ve yükleme alanı

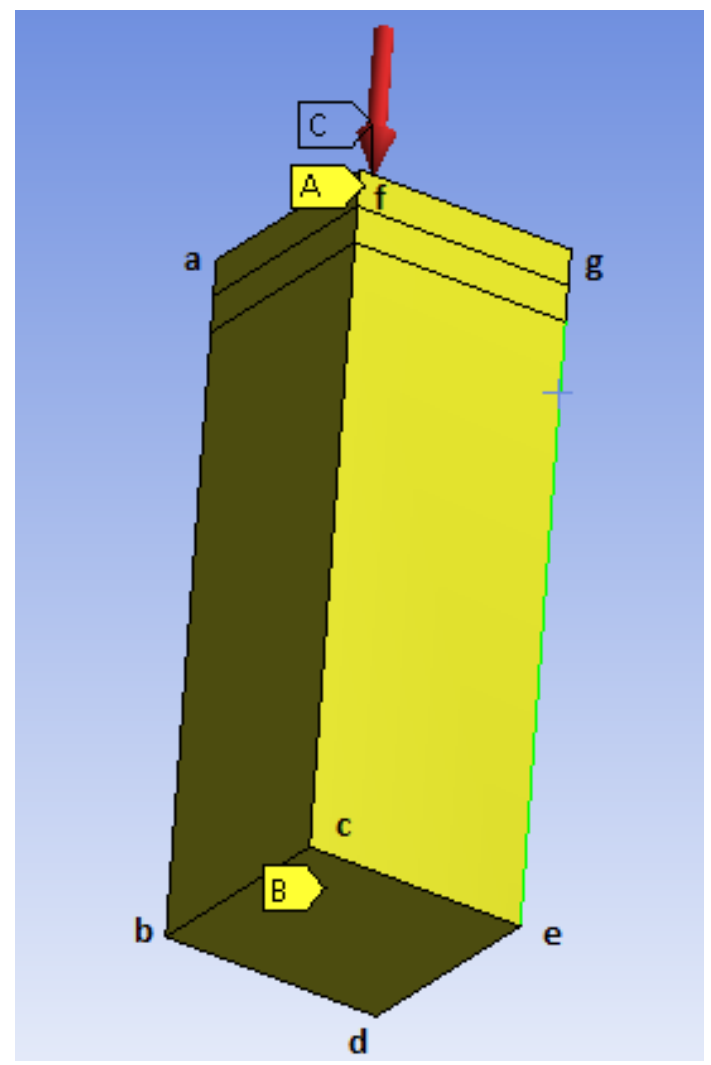

Şekil 2. Sınır koşulları
Modelden elde edilen sonuçların doğrulanması amaciyla Huang (2004) tarafından geliştirilen ve mekanistik-ampirik kaplama analizlerinde referans kabul edilen (Muniandy vd., 2013; Sarkar, 2016; Chegenizadeh vd., 2016; Hafeez vd., 2017) Kenlayer paket programı kullanılmıştır. Belirlenen kesitin Kenlayer ile çözümünde kaplama tabakası üst yüzeyi için elde edilen deplasman değeri $(0.56 \mathrm{~mm})$ oluşturulan modelde plan boyutlar1 $950 \times 950 \mathrm{~mm}$ ve taban zemini derinliği $2540 \mathrm{~mm}$ olarak seçildiğinde $0.55 \mathrm{~mm}$ olarak bulunmuş ve $\% 98$ oranında bir uyumluluk elde edilmiştir.

\subsection{Yol Hizmet Ömrünün Tahmin Edilmesi}

Mekanistik-ampirik dizayn yöntemlerinin kullanılabilmesi için elde edilen gerilme, birim şekil değiştirme veya deplasman değerlerinin kaplama davranışını (çatlama, tekerlek izinde oturma, pürüzlülük vd.) yansitan bir parametreye dönüştürülmesi gerekmektedir (Ekwulo ve Eme, 2009). Yorulma çatlakları kaplamada tekrarlı yüklemeye bağlı olarak ortaya çıkan bir bozulma tipidir. Mekanistik-ampirik dizayn yönteminde 
yorulma kriteri olarak asfalt betonu tabakası altında meydana gelen çekme birim şekil değiştirmeleri kullanılmaktadır. Bu birim şekil değiştirme değerlerinin belirli bir sınırı aşması durumunda kaplamada çatlaklar meydana gelmektedir. Asfalt Enstitüsü ve Shell yöntemleri ile yorulmaya bağlı göçmeyi sağlayan yük tekrar sayısı formülleri sırasıyla aşağıda belirtilmiştir (Ekwulo ve Eme, 2009; Adhikari vd., 2009).

$N_{f}=0.0796\left(\varepsilon_{t}\right)^{-3.291}\left(E_{1}\right)^{-0.854}$

$N_{f}=0.0685\left(\varepsilon_{t}\right)^{-5.671}\left(E_{1}\right)^{-2.363}$

Formüllerde $\mathrm{N}_{\mathrm{f}}$ göçmeyi meydana getiren yük tekrar sayısını, $\varepsilon_{\mathrm{t}}$ kaplama tabakası altındaki yatay birim şekil değiştirmeyi, $\mathrm{E}_{1}$ ise kaplama tabakasının elastisite modülünü (psi) belirtmektedir.

Asfalt Enstitüsü ve Shell tarafindan önerilen ve kaplamada meydana gelen tekerlek izinde oturmaya bağlı göçme ile taban zemini üzerindeki düşey basınç birim şekil değiştirmesi arasındaki ilişki Formül 3 ve 4'te belirtilmiştir.

$$
\begin{aligned}
& N_{f}=1.365 \times 10^{-9}\left(\varepsilon_{c}\right)^{-4.477} \\
& N_{f}=6.15 \times 10^{-7}\left(\varepsilon_{c}\right)^{-4}
\end{aligned}
$$

Formüllerde $\mathrm{N}_{\mathrm{f}}$ tekerlek izinde oturma göçmesini meydana getiren yük tekrar sayısını, $\varepsilon_{\mathrm{c}}$ ise taban zemini üzerindeki basınç birim şekil değiştirmesini göstermektedir (Hesham ve Shiraz, 1998; Ekwulo ve Eme, 2009).

\section{Bulgular ve Tartışma}

Sonlu elemanlar yönteminde plan ve kesit boyutlarının (Şekil 3) seçimi sonuca önemli ölçüde etki etmektedir. Plan boyutlarının etkinliğini incelemek amacıyla farklı kenar uzunlukları için analizler yapılarak üst yapıdaki maksimum deplasman değerleri hesaplanmış ve sonuçlar Tablo 1'de verilmiştir.

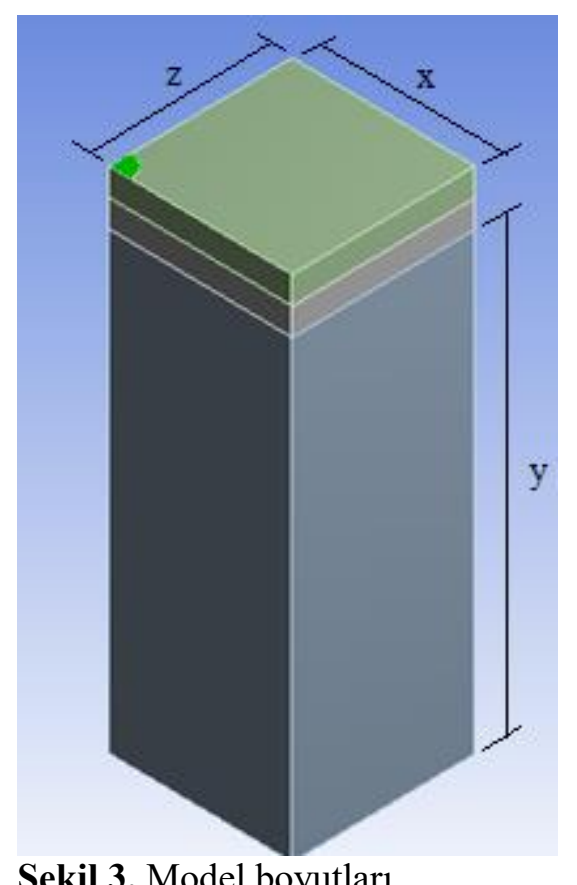

Şekil 3. Model boyutları

Tablo 1. Plan boyutlarına bağlı deplasman değerleri

\begin{tabular}{llll}
\hline Yükleme yarıçapı (r)(mm) & Plan boyutları $(\mathbf{x}-\mathbf{z})(\mathbf{m m})$ & $\mathbf{r} / \mathbf{x}$ & Maksimum deplasman $(\mathbf{m m})$ \\
\hline 122 & 1350x1350 & 0.090 & 0.41 \\
122 & 1100x1100 & 0.111 & 0.48 \\
122 & 1050x1050 & 0.116 & 0.50 \\
122 & 1000x1000 & 0.122 & 0.52 \\
122 & $950 \times 950$ & 0.128 & 0.55 \\
122 & $900 x 900$ & 0.135 & 0.58 \\
\hline
\end{tabular}


Tablo 1 incelendiğinde kenar boyutlarının artışına bağlı olarak deplasman değerlerinin düştüğü gözlenmektedir. Kenar uzunluklarındaki artışın yükleme noktası etrafindaki yanal desteği artırması düşen deplasman değerlerini açıklamaktadır.

Taban zemini derinliği $2540 \mathrm{~mm}$ sabit olmak üzere farklı plan boyutlarının yol ömrü üzerindeki etkisinin sayısal değerler ile kıyaslanmasını sağlamak amaciyla taban zemini üzerinde meydana gelen düşey birim şekil değiştirme $\left(\varepsilon_{\mathrm{c}}\right)$ ve buna bağl1 Shell yöntemi ile hesaplanan yol ömrü değerleri $\left(\mathrm{N}_{\mathrm{f}}\right)$ Tablo 2'de verilmiştir. $\mathrm{N}_{\mathrm{f}}$ değerleri incelendiğinde plan boyutlarının artmasına bağlı olarak düşey birim şekil değiştirme değerlerinde bir azalma ve buna bağlı olarak yol ömründe yaklaşık \%25 bir artış söz konusudur. $\mathrm{Bu}$ sonuçlara göre plan boyutlarının seçimi yol ömrüne bağlı analizlerde mutlaka göz önünde bulundurulması gereken önemli bir parametre olarak değerlendirilmelidir.

Tablo 2. Plan boyutlarına bağlı düşey birim şekil değiştirme ve yol ömrü değerleri

\begin{tabular}{lll}
\hline Plan boyutları $(\mathbf{x}-\mathbf{z})(\mathbf{m m})$ & $\boldsymbol{\varepsilon}_{\mathbf{c}}$ & $\mathbf{N}_{\mathbf{f}}$ \\
\hline $900 \times 900$ & $5.14 \times 10^{-4}$ & $8.81 \mathrm{E}+06$ \\
$950 \times 950$ & $5.04 \times 10^{-4}$ & $9.53 \mathrm{E}+06$ \\
$1000 \times 1000$ & $4.96 \times 10^{-4}$ & $1.02 \mathrm{E}+07$ \\
$1050 \times 1050$ & $4.91 \times 10^{-4}$ & $1.06 \mathrm{E}+07$ \\
$1100 \times 1100$ & $4.86 \times 10^{-4}$ & $1.10 \mathrm{E}+07$ \\
\hline
\end{tabular}

Şekil 4'te verilen ve yarı sonsuz tabaka derinliği (y) olarak adlandırılan taban zemini kalınlığ 1 değişimine bağlı deplasman değerleri incelendiğinde taban zemini kalınlığ deplasman değerlerinin de azaldığı görülmektedir. Plan boyutlarının 950x950 olarak belirlendiği bu analizde deplasman değerlerinin azalmasını sağlayan en önemli parametre sınır koşullarında düşey deplasmanı engellenmiş olan taban düzlemine olan mesafenin kısalmasıdır. Düşey doğrultuda rijit davranış gösteren yüzeye olan mesafe kısaldıkça deplasman değerleri de düşmüştür. Kenlayer programı ile elde edilen deplasman değerini sağlayan temel derinliği/taban zemini derinliği oranı grafikten 0.06 olarak okunmaktadır. Buna bağlı olarak hesaplanan taban zemini derinliği ise $2540 \mathrm{~mm}$ dir. Boyutsal analizden elde edilen bu değerler 1şığında yarı sonsuz tabaka derinliğinin plan boyutlarına oranla 2.67 kat fazla olması gerektiği söylenebilir.

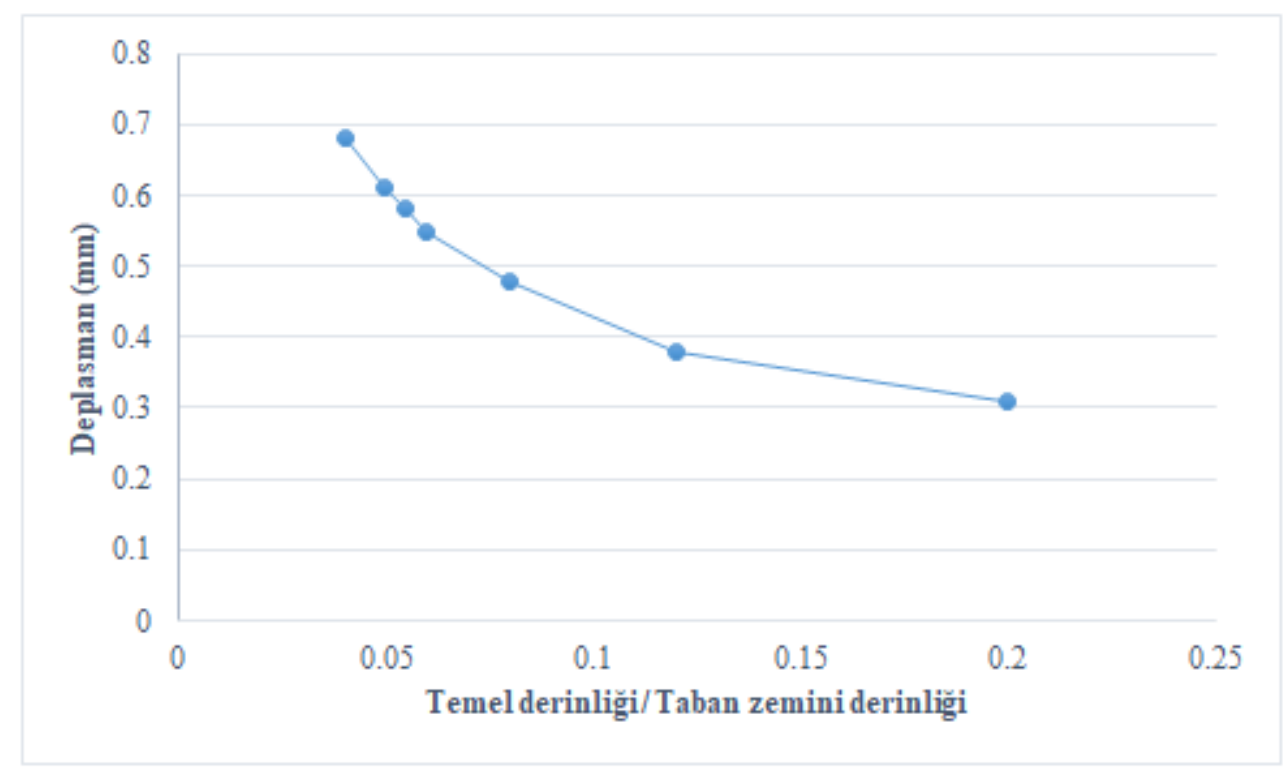

Şekil 4. Taban zemini derinliğine bağlı deplasman değişimi

Sınır koşullarının tanımlanması sonlu elemanlar yönteminde sonuçlara etki eden bir diğer önemli parametredir, çalışmada daha önceden de tanımlandığı gibi taban düzlemi, simetri düzlemi ve tekerlek ortasından geçen düzlem düşeyde deplasman yapmayacak şekilde tanımlanmıştır bu sınır koşullarına ilave olarak yolun trafik akış yönündeki derinliğinin fazla olması sebebiyle bu akış yönünde dikey olan düzlemin de (Şekil 2'ye referans ile (cefg) düzlemine paralel karşı düzlem) 
düşey deplasmanları sınırlanarak analizler yapılmıştır. $\mathrm{Bu}$ kapsamda çalışmanın başlangıcındaki sınır koşulları (boundary condition) 3 düzlemi kapsadığından "3BC", trafik doğrultusuna dik düzlemin de kısıtlanması ile oluşan yeni model "4BC" olarak tanımlanmış ve bu iki farklı durumda oluşan deplasman değerleri plan boyutlarının değişimine bağlı olarak Şekil 5 'te verilmiştir.

Şekil 5 incelendiğinde trafik doğrultusuna dik olan düzlemde ek bir sınır koşulu tanımlamak deplasman değerlerinde \%18-22 arasında bir düşüşe sebep olmaktadır, rijit düğüm noktası sayısının artması deplasman değerlerinde önemli bir fark ortaya koymaktadır ve şekilden de görüleceği gibi plan boyutlarının azalması deplasman değerlerinin daha fazla düşmesini sağlamaktadır. 3BC modeli ile 4BC modeli arasındaki farkların beton yollar gibi daha rijit kaplama tiplerinde birbirine yakın sonuçlar vereceği değerlendirilebilir. Ancak esnek kaplamalar üzerlerine gelen tekerlek iç basınçlarını beton yollara nazaran daha az bir alana yayabildikleri için 4BC modeli ile çalışmak yerine $3 \mathrm{BC}$ modeli ile çalışmak daha uygun bir çözüm olarak ifade edilebilir.

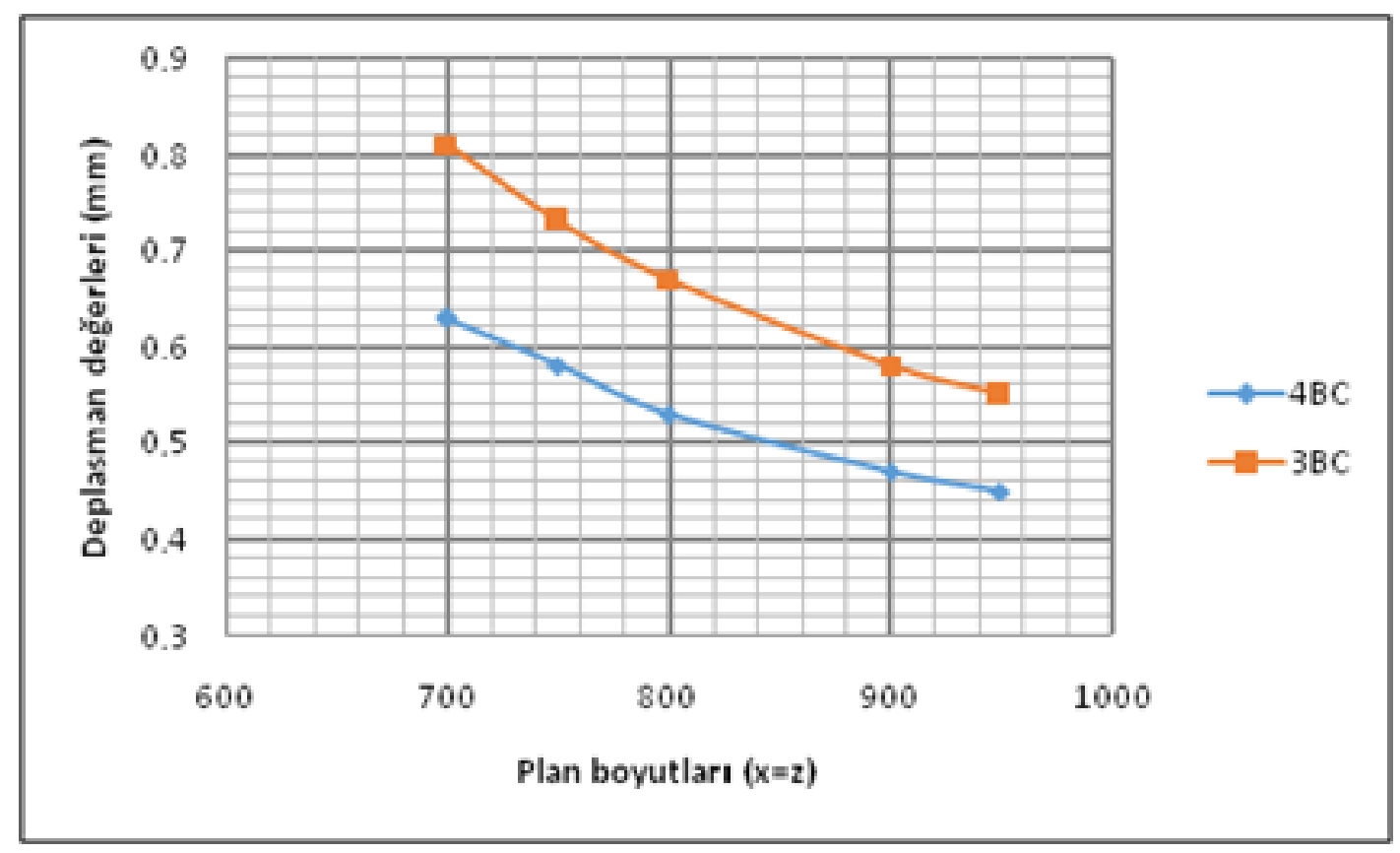

Şekil 5. Sınır koşullarına bağlı deplasman değerleri

Izgara (mesh) boyutlarının seçimi sonlu elemanlar yönteminin sonuçlara etki eden en önemli parametrelerinden birisidir, büyük ızgara boyutları yakınsak olmayan sonuçlar verirken küçülen 1zgara boyutları ise çözüm süresinin oldukça uzamasına sebebiyet vermekte ve özellikle birden çok analizin yapılacağ zaman kayıplarına yol açmaktadır. Çalışmada karayolu kaplamasının deplasman değerlerine ızgara boyutlarının etkisini değerlendirmek amacıyla 3 farklı çalışma yapıııışıır (Şekil 6). Bu çalışmalarda yükün uygulandığ $1 / 44$ daire alandaki 1zgara boyutları, kaplama tabakasının ızgara boyutları ve temel tabakasinın 1zgara boyutları üzerindeki değişimlerin sonuca etkileri araştırılmıştır. Izgara analizi yapılırken plan boyutlar1 950x950 mm, yar1 sonsuz tabaka derinliği $2540 \mathrm{~mm}$ ve boyut fonksiyonu "uniform" olarak çalışılmıştır. Yük altındaki bölgede yapılan inceltme işlemine ve kaplama tabakasını oluşturan dikdörtgen prizmanın maksimum yüzey boyutuna bağlı deplasman sonuçları Tablo 3'te, temel tabakası kalınlığının (152.4 mm) bölünme boyutuna bağlı deplasman değerleri ise Tablo 4 'te özetlenmiştir.

Sonuçlar incelendiğinde yük altındaki bölgede ızgara boyutlarının incelmesi sonuçlar üzerinde çok etkili değilken kaplama tabakası yüzey boyutları sonuçlar üzerinde $\% 0.4$ oranında etki göstermiştir. Yükü doğrudan almayan temel tabakasındaki ızgara boyutu değişimi ise sonuçlar hiçbir farklılık ortaya çıkartmamıştır. Bu sonuçlara göre 1zgara boyutları seçiminin, çalışılan modelin etkin sonuçlar vermesi açısından birinci derece öneme sahip bir parametre olmadığ 1 belirtilebilir. 

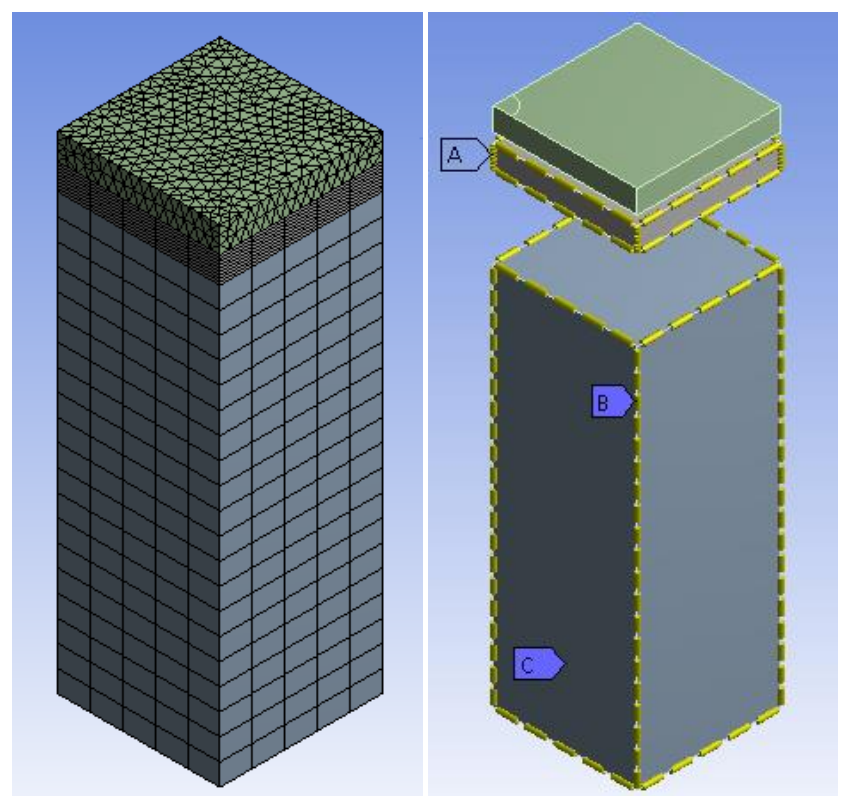

Şekil 6. Model 1zgara analizi

Tablo 3. Izgara boyutlarına bağlı deplasman değerleri (mm)

\begin{tabular}{|c|c|c|c|c|c|c|c|c|c|}
\hline \multirow[b]{2}{*}{$\begin{array}{c}\text { Analiz } \\
\text { bölgesi }\end{array}$} & \multicolumn{9}{|c|}{ Izgara inceltme seviyesi / Maksimum yüzey boyutu (mm) } \\
\hline & $\begin{array}{c}\text { İnceltme } 1 \\
\text { (Kalın) }\end{array}$ & $\begin{array}{l}\text { İnceltme } \\
2 \text { (Orta) } \\
\end{array}$ & $\begin{array}{c}\text { İnceltme } \\
\mathbf{3} \text { (İnce) } \\
\end{array}$ & 60 & 50 & 40 & 30 & 20 & 10 \\
\hline $\begin{array}{l}1 / 4 \text { daire } \\
\text { Kaplama }\end{array}$ & 0.55049 & 0.55062 & 0.55069 & 0.5497 & 0.55023 & 0.55128 & 0.55138 & 0.55169 & 0.55198 \\
\hline
\end{tabular}

Tablo 4. Temel tabakası kalınlığı bölme boyutuna bağlı deplasman değerleri (mm)

\begin{tabular}{ccccc}
\hline Analiz bölgesi & \multicolumn{4}{c}{ Temel tabakası kalınlığı bölme boyutu (mm) } \\
\cline { 2 - 5 } & $\mathbf{5 0}$ & $\mathbf{3 8}$ & $\mathbf{4 . 7 5}$ & $\mathbf{9 . 5}$ \\
\cline { 2 - 5 } Temel & 0.54969 & 0.54969 & 0.5497 & 0.5497 \\
\hline
\end{tabular}

Sonlu elemanlar yönteminde birbirinden farkl1 malzeme özelliklerine sahip yüzeyler arasında temas denklemleri kurulmasi gerekmektedir. Ĕger uygun temas denklemi seçilmez ise yük altında, bir kütlenin kendisinden farklı mekanik özellikteki kütle içerisine girmesi/batması sonucu ortaya çıkmaktadır (Şekil 7). Bu durum üst yapı analizlerinde tekerlek-kaplama veya kaplamatemel ara yüzeylerinde gerçekleşebilir ancak fiziksel olarak mümkün olmayan bu durumun engellenmesi için ANSYS paket programında temas formülasyonu olarak "Multi Point Constraint (MPC)" seçimi yapılmalıdır. Bu formülasyon temas yüzeyleri arasinda deplasmanları birbirine bağlayan kısıt denklemleri ekleyerek temas yüzeyindeki iki dügüum noktasının deplasmanlarını birbirine eşitlemektedir.

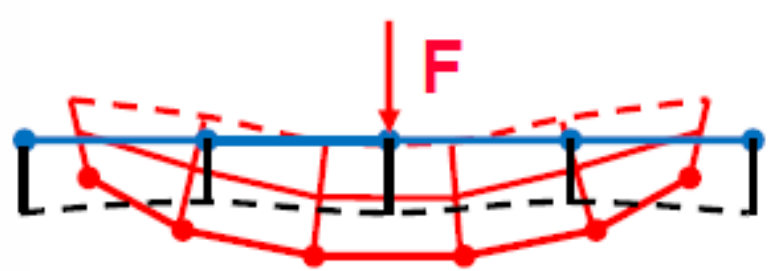

Şekil 7. Temas kütlesinin hedef kütle içerine batmas1

\section{Sonuçlar ve Öneriler}

Karayolu esnek üst yapı tabakalarının sonlu elemanlar yöntemi ile analiz edilmesinde model sonuçlarına etki eden parametrelerin incelendiği bu çalışmaya ait bulgular ışığında aşağıdaki sonuçlar ifade edilebilir; 
- Plan boyutlarının seçimi sonlu elemanlar analizinde önemli parametrelerden bir tanesidir ve bu boyutların fazla veya eksik olarak tanımlanması elde edilen deplasman değerlerini önemli ölçüde etkilemektedir. Çalışmada yükleme yarıçapı/plan boyutu oranının optimum değeri 0.128 olarak bulunmuştur.

- Plan boyutlarının yol ömrü hesaplarına etkisini değerlendirmek amaciyla yapılan analizlerde 900x900 mm yerine 1100x1100 mm kare kesitli bir model ile çalışıldığında tekerlek izinde oturma kriterine bağl1 yol ömrü değerinde \%25 oranında bir artış olduğu belirlenmiştir. $\mathrm{Bu}$ sonuçlar birim şekil değiştirme ve buna bağl1 dönüşüm formülleri ile yol ömrü hesaplamalarında plan boyutları seçiminin çok önemli bir kriter olduğunu ortaya koymaktadır.

- Modeli oluşturan tabakalardan en altta yer alan ve yarı sonsuz tabaka olarak adlandirilan taban zemini derinliği, taban düzleminin düşey deplasmanlarının engellenmesi sebebiyle sonuçlar üzerinde önemli bir etkiye sahiptir. $\mathrm{Bu}$ tabakanın derinliğinin az seçilmesi deplasman değerlerini azaltırken fazla seçiminde ise deplasman değerleri önemli ölçüde artmaktadır. Temel tabakası derinliği / taban zemini derinliği oranında optimum değerin $\% 6$ olduğu belirtilebilir.

- Kare prizma olarak tanımlanan modeli meydana getiren 6 yüzeyden 3 veya 4 tanesinde düşey sınır koşulu tanımlayarak çalıştırılan analizlerde trafik yönüne dik doğrultudaki yüzeyin de düşey deplasmanlarının sinırlandırılması elde edilen deplasman değerlerinde \%18-22 arasında bir düşüşe sebep olduğu ancak bu kısitın esnek kaplamalar yerine rijit kaplamalar için daha uygun bir sınır koşulu olacağı değerlendirilmiştir.

- Izgara boyutlarının değerlendirilmesi için yapılan çalışmalarda yüke doğrudan temas eden kaplama tabakasındaki dügüm noktası sayısının artmasının modelin yakınsaması üzerinde çok az bir etkiye sahip olduğu belirlenmiş ancak yükü doğrudan almayan temel tabakasındaki 1zgara boyutlarının sonuçlara bir etkisinin olmadığı gözlenmiştir. Izgara boyutlarındaki azalmanın ve dügüm noktası sayısındaki artışın çözüm süresini de artırdığı göz önüne alındığında çok ince ızgaralar ile çalışmanın gerekli olmadığı söylenebilir.

- Kaplama analizlerinde fiziksel olarak tabakaların veya kaplama üzerindeki tekerleğin birbirleri içerisine batma durumu düşünülmediğinden beraber hareket eden yüzeylere ortak düğüm noktaları tanımlamayı sağlayan MPC temas formülasyonunun uygun bir analiz parametresi olduğu düşünülmektedir.

\section{Teșekkür}

Bu çalışma, Cumhuriyet Üniversitesi Bilimsel Araştırma Projeleri (CÜBAP) tarafindan M-682 proje numarası ile desteklenmiştir.

\section{Kaynakça}

Abd Alla, E.M., 2006. The rational use of finite element method in the analysis of flexible pavements. Journal of Engineering Sciences, Assiut University, 34, 1185-1211.

Adhikari, S., Shen, S. ve You, Z., 2009. Evaluation of fatigue models of hot-mix asphalt through laboratory testing. Transportation Research Record Journal of the Transportation Research Board, 2127, 36-42.

Ahirwar, S.K. ve Mandal, J.N., 2017. Finite element analysis of flexible pavement with geogrids. Procedia Engineering, 189, 411416.

Ahmed, A. ve Erlingsson, S., 2016. Viscoelastic response modelling of a pavement under moving load. Transportation Research Procedia, 14, 748-757.

Al-Azzawi, A.A., 2012. Finite element analysis of flexible pavements strenghted with geogrid. ARPN Journal of Engineering and Applied Sciences, 7, 1295-1299.

Ali, H.A. ve Tayabji, S.D., 1998. Mechanistic evaluation of test data from LTPP flexible pavement test sections, US Department of Transportation Federal Highway Administration, Report no. FHWA-RD-98012

Ambassa, Z., Allou, F., Petit, C. ve Eko, R.M., 2013. Fatigue life prediction of an asphalt pavement subjected to multiple axle loadings with viscoelastic FEM. Constrğuction and Building Materials, 43, 443-452.

Beskou, N.D., Tsinopoulos, S.V. ve Theodorakopoulos, D.D., 2016. Dynamic elastic analysis of 3-D flexible pavements under moving vehicles: A unified FEM 
treatment. Soil Dynamics and Earthquake Engineering, 82, 63-72.

Chegenizadeh, A., Keramatikerman, M. ve Nikraz, H., 2016. Flexible pavemet modelling using Kenlayer. EJGE, 21, 24672479.

Ekwulo, E.O. ve Eme, D.B., 2009. Fatigue and rutting strain analysis of flexible pavements designed using CBR methods. African Journal of Environmental Science and Technology, 3, 412-421.

Hadi, M.N.S. ve Bodhinayake, B.C., 2003. Nonlinear finite element analysis of flexible pavements. Advances in Engineering Software, 34, 657-662.

Hafeez, I., Shan, A., Ali, A. ve Ahmed, I., 2017. Flexible pavement design evaluation using mechanistic-empirical approaches.

Technical Journal, University of Engineering and Technology, 22, 27-33.

Huang, Y.H., 2004. Pavement Analysis and Design, Pearson Prentice Hall, New Jersey.

Lu, P., Bratlien, A. ve Tolliver, D., 2014. North Dakota Implementation of Mechanistic-
Empirical Pavement Design Guide (MEPDG), Mountain-Plains Consortium, North Dakota.

Muniandy, R., Aburkaba, E. ve Thamer, N., 2013. Comparison of flexible pavement performance using Kenlayer and Chev PC software program. Australian Journal of Basic and Applied Sciences, 7, 112-119.

Sarkar, A., 2016. Numerical comparison of flexible pavement dynamic response under different axles. International Journal of Pavement Engineering, 17, 377-387.

Yoo, P.J., Al-Qadi, L.L., Elseifi, M.A. ve Janajreh, I., 2006. Flexible pavement responses to different loading amplitudes considering layer interface condition and lateral shear forces. The International Journal of Pavement Engineering, 7, 73-86.

Zheng, L., Hai-lin, Y., Wan-ping, W. ve Ping, C., 2012. Dynamic stres and deformation of a layered road structure under vehicle traffic loads: Experimental measurements and numerical calculations. Soil Dynamics and Earthquake Engineering, 39, 100-112. 